\title{
Lusioersily
}

\section{Folic Acid Supplementation throughout pregnancy: psychological developmental benefits for children}

Henry, L-A., Cassidy, T., McLaughlin, M., Pentieva, K., McNulty, H., Walsh, C., \& Lees Murdock, D. (2018). Folic Acid Supplementation throughout pregnancy: psychological developmental benefits for children. Acta Paediatrica, 107(8), 1370-1378. https://doi.org/10.1111/apa.14290

Link to publication record in Ulster University Research Portal

\section{Published in:}

Acta Paediatrica

Publication Status:

Published (in print/issue): 13/07/2018

DOI:

10.1111/apa.14290

\section{Document Version}

Author Accepted version

\section{General rights}

Copyright for the publications made accessible via Ulster University's Research Portal is retained by the author(s) and / or other copyright owners and it is a condition of accessing these publications that users recognise and abide by the legal requirements associated with these rights.

\section{Take down policy}

The Research Portal is Ulster University's institutional repository that provides access to Ulster's research outputs. Every effort has been made to ensure that content in the Research Portal does not infringe any person's rights, or applicable UK laws. If you discover content in the Research Portal that you believe breaches copyright or violates any law, please contact pure-support@ulster.ac.uk. 


\title{
Folic Acid Supplementation throughout pregnancy: psychological developmental benefits for children
}

Lesley-Anne Henry, Tony Cassidy (t.cassidy@ulster.ac.uk) iD, Marian McLaughlin, Kristina Pentieva, Helene McNulty, Colum P. Walsh, Diane Lees-Murdock

Ulster University, Coleraine, UK

\section{Keywords}

Emotional intelligence, Folic acid, Prosocial behaviour, Psychological adjustment, Resilience

\section{Correspondence}

Tony Cassidy, Psychology Institute, Ulster University, Cromore Road, Coleraine, BT52 1SA UK.

Tel: +44 (0) 2870123025 |

Fax: +44 (0) 2870124897 |

Email: t.cassidy@ulster.ac.uk

\section{Received}

14 August 2017; revised 13 February 2018; accepted 16 February 2018.

DOI:10.1111/apa.14290

\begin{abstract}
Aim: To test the effect of folic acid supplements taken throughout pregnancy on children's psychosocial development.

Method: A randomised controlled trial of folic acid supplementation in pregnancy, with parental rating using the Resiliency Attitudes and Skills Profile (RASP), the Strengths and Difficulties Questionnaire (SDQ) and the Trait Emotional Intelligence Questionnaire Child Short Form (TEIQue-CSF). Children aged 6-7 whose mothers received folic acid throughout pregnancy $(n=22)$ were compared to those whose mothers only received it during the first trimester $(n=17)$.

Results: Children whose mothers received the full-term supplement scored significantly higher on emotional intelligence and resilience. Hierarchical multiple regression analysis identified folate level at 36th gestational week as an important predictor of emotional intelligence (EI) and resilience.

Conclusion: Although conclusions must be drawn with caution, this research presents a number of potential implications, the main one being a proposed policy recommendation for women to take folic acid for the duration of pregnancy rather than stopping at the end of the first trimester. The second is the potential for future research to explore the possible psychological and social development benefits and in line with this to try and identify the explanatory mechanism involved.
\end{abstract}

\section{INTRODUCTION}

Pregnancy is a time when nutritional needs are increased due to physiological changes of the mother and the metabolic demands of the embryo/foetus (1). During this period, proper maternal nutrition is vital for optimal health for both mother and child. Folate has been identified as one particular micronutrient crucial for development particularly during the periconceptional period (about one month before and one month after conception), providing a range of benefits for both the mother and child (2). Folate is essential to synthesise, repair and methylate DNA; therefore, the demand for folate increases during pregnancy to

\footnotetext{
Abbreviations

BMI, Body mass index; EI, Emotional intelligence; FASSTT, Folic acid supplementation in the second and third trimester; GW, Gestational week; HMRA, Hierarchical multiple regression analysis; HSC, Health and social care; MABC, Ma'anshan-Anhui birth cohort study; NTD, Neural tube deficits; ORECNI, Office of Research Ethics Committee in Northern Ireland; RASP, Resiliency attitudes and skills profile; RCT, Randomised control trial; SDQ, Strengths and difficulties questionnaire; TEIQue-CSF, Trait emotional intelligence questionnaire child short form.
}

aid rapid cell division and growth which is vital for foetal, placental and maternal growth and development (3).

Substantial evidence exists regarding the protective effect of folic acid supplementation during the first trimester against neural tube deficits (NTDs) (4) and other physical health issues (e.g. low infant birthweight and pre-eclampsia) (5). This evidence has led to clear recommendations by governments worldwide for women of reproductive age to take $400 \mu \mathrm{g} /$ day folic acid from preconception to the end of first trimester (6) and has led to mandatory food

\section{Key notes}

- Effects of folic acid supplementation during the first trimester of pregnancy have been tested, but little is known of the effects of continued supplementation throughout pregnancy.

- This small randomised control study has found that children whose mothers continued supplementation for the duration of pregnancy exhibited higher scores on emotional intelligence and resilience.

- The study provides a basis for future research which may impact on clinical guidelines for folic acid supplementation. 
fortification programmes (7). There is also evidence to suggest that higher folate status will have a positive impact on children's cognitive and neurological development (8). This raises questions about whether the benefits of supplementation extend to other aspects of psychological development in children. It is generally recognised that cognitive development goes hand in hand with socio-emotional development in children and that both are built into brain development (9); emotional intelligence and resilience being of particular interest $(10,11)$.

Emotional intelligence (EI) refers to the ability to perceive, control and evaluate emotions, including the person's ability to carry out accurate reasoning about emotions and the ability to use emotions and emotional knowledge to enhance thought (12). Resilience is defined as bounce back ability in the face of adversity, commonly described as positive or protective processes that reduce maladaptive outcomes under conditions of risk $(11,13)$. EI and resilience often provide children with protection against internalising and externalising problems which pose a variety of social, emotional and psychological difficulties for the child during childhood and in adult life (14).

It is unlikely that folic acid would have a direct impact on psychological attributes. but it could be argued that the physical health benefits from supplementation could promote healthy psychological development through a range of environmental factors. The World Health Organisation (15) identified that poor physical health in infancy can lead to difficulties with feeding and that physical and neurological health problems increase as birthweight decreases (16). This in turn can cause developmental vulnerabilities in the child's temperament (17).

To date, most research has focused on maternal folate intake during the first trimester due to the Department of Health recommendations; however, few studies have considered the impact of supplemental folic acid during the second and third trimester and from those that have findings are inconclusive. One study from the Ma'anshanAnhui Birth Cohort Study (MABC) in China found that continued supplementation throughout pregnancy was associated with increased birthweight of offspring (18). However, this was an observational study based on mothers' self-reports of folate intake and it is not clear if effects were negative. The only randomised control trial (RCT) in the area found that continued supplementation can increase maternal and cord blood folate status and prevent the increase in homocysteine concentration that otherwise occurs in late pregnancy and recommends further study (19).

The aim of this study was to follow up a subsample of mothers and children from the original Folic Acid Supplementation in the Second and Third Trimester (FASSTT) study (Fig. 1) to assess strengths and difficulties, emotional intelligence and resilience in the children now aged seven years. It was hypothesised that children of mother's who continue to take folic acid supplements throughout pregnancy would exhibit differences in a positive direction in strengths and difficulties, EI and resilience from those who discontinued supplementation at the recommended 12 weeks. Furthermore, it was hypothesised that higher levels of folate will predict higher scores on emotional intelligence and resilience.

\section{METHODOLOGY \\ Design}

The original RCT (registered at controlled-trials.com as ISRCTN19917787) was conducted in 2006 and has been described in detail elsewhere (19). Briefly, this study investigated the effect of Folic Acid Supplementation in the Second and Third Trimester and the health outcomes of the mother and newborn (FASSTT study; ISRCTN19917787). Healthy pregnant women $(\mathrm{n}=119)$ aged $18-35$ years, with singleton pregnancies and without pregnancy complications, who had taken folic acid supplementation during the first trimester of pregnancy (as universally recommended) were recruited from antenatal clinics at the 14th gestational week. At the beginning of the second trimester, participants were randomly assigned to receive either $400 \mu \mathrm{g} /$ day of folic acid or a placebo for 26 weeks. This study was a follow-up investigation when children were seven years old (See Fig. 1 for diagrammatic protocol).

\section{Participants}

Mother-child pairs were recruited from the participants of the original FASSTT study when the child was aged six to seven years ( $\mathrm{M}=6.74$, range $6.3-7.3$ years). A total of 39 children (14 male children and 25 female children) were assessed during the current study. Participants in the original study were randomly assigned to an experimental group $(\mathrm{n}=22)$ who continued folic acid supplements throughout the pregnancy duration, and a control group $(n=17)$ who received a placebo instead of folic acid supplementation after the required 12 weeks. Participants were assigned a unique identification code to ensure confidentiality and anonymity. For this study, we recruited 22 mother-child pairs from the experimental condition and 17 mother-child pairs from the control condition.

\section{Measures}

Demographical details including the child's age, sex and anthropometric measurements (height, weight, waist circumference, head circumference and body fat) were retrieved from the original study. Mothers were then asked to rate their child on the Resiliency Attitudes and Skills Profile (RASP) and the Strengths and Difficulties Questionnaire (SDQ), and the Trait Emotional Intelligence Questionnaire Child Short Form (TEIQue-CSF).

The Resiliency Attitudes and Skills Profile (RASP) (20) is a 25-item scale which measures seven dimensions of resilience (creativity, humour, independence, initiative, insight, relationships and values orientation). It asks parents to rate items relating to how the child copes with everyday challenges on a seven-point scale ranging from 'disagree completely' to 'agree completely'. Higher scores 


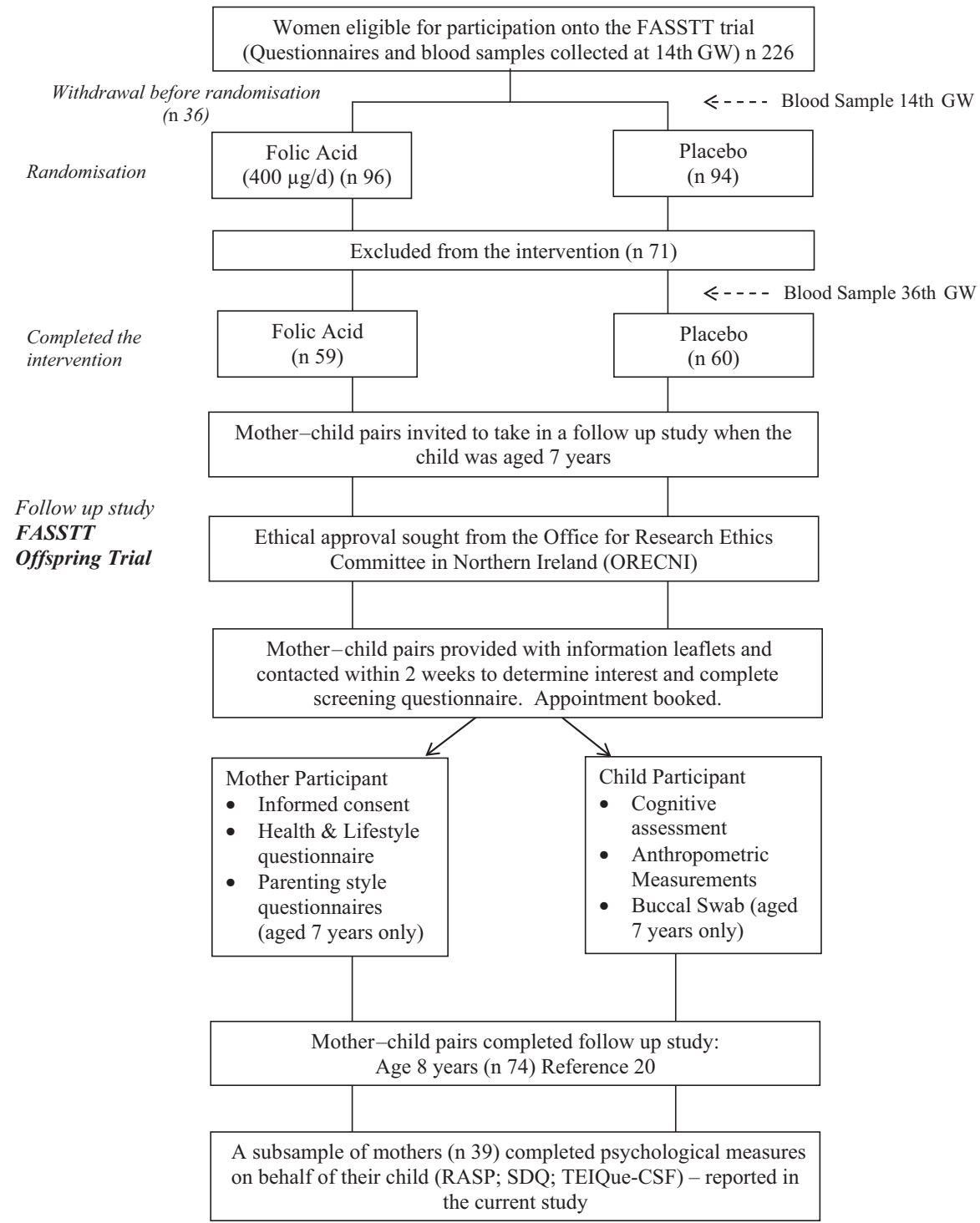

Figure 1 Diagrammatic protocol of the FASSTT offspring trial.

Table 1 Levels of serum folate present in experimental and control group members at 14th and 36th Gestational Weeks and at birth

\begin{tabular}{|c|c|c|c|c|c|c|c|}
\hline & \multirow[b]{2}{*}{ Variable } & \multicolumn{2}{|c|}{ Experimental $(n=22)$} & \multicolumn{2}{|c|}{ Control $(n=17)$} & \multirow[b]{2}{*}{ Mann-Whitney $U$-value } & \multirow[b]{2}{*}{$\mathrm{p}$} \\
\hline & & Median & Interquartile range & Median & Interquartile range & & \\
\hline \multirow[t]{2}{*}{ 14th GW } & Serum Folate (ng/mL) & 18.25 & 14.22 & 21.79 & 16.98 & 160.00 & 0.444 \\
\hline & Serum Folate (nmol/L) & 58.02 & 45.22 & 69.29 & 54.00 & 160.00 & 0.444 \\
\hline \multirow[t]{2}{*}{ 36th GW } & Serum Folate (ng/mL) & 16.79 & 20.78 & 8.44 & 10.50 & 63.00 & 0.007 \\
\hline & Serum Folate (nmol/L) & 53.41 & 66.07 & 26.84 & 33.39 & 94.50 & 0.009 \\
\hline \multirow[t]{2}{*}{ At birth } & Serum Folate (ng/mL) & 37.57 & 17.77 & 22.69 & 12.34 & 37.00 & 0.01 \\
\hline & Serum Folate (nmol/L) & 119.49 & 56.49 & 72.15 & 39.23 & 98.00 & 0.01 \\
\hline
\end{tabular}

reflect more resilience. The RASP has been found to have adequate internal consistency, concurrent validity, convergent and discriminant validity (20). In the present sample, the Cronbach's alpha was 0.95 for the parent reported child resilience.
The Strengths and Difficulties Questionnaire (SDQ) is one of the most widely used brief questionnaires for assessing child problems (21). It is a brief multidimensional measure of psychological adjustment of children aged three to 16 years. It is freely available as both a self-report and a 
proxy report questionnaire and has been translated into 60 languages. The SDQ is comprised of 25 items which are divided into five scales, each with five items. These items generate scores for Conduct Problems $(a=0.81)$, Hyperactivity $(a=0.86)$, Emotional Symptoms $(a=0.83)$, Peer Problems $(a=0.80)$ and Prosocial Behaviour $(a=0.78)$. Each item is rated with a three-point Likert-type scale of not true (score 0 ), somewhat true (score 1) and certainly true (score 2), the total difficulties score is the summed score of the conduct, hyperactivity, emotional and peer problem scales, giving a possible total between 0 and 40 . The prosocial behaviour scale is the only scale rated in a positive direction and provides a separate measure. The mother rating version was used in this study, as the self-report version is unsuitable for children of this age.

The Trait Emotional Intelligence Questionnaire Child Short Form (TEIQue-CSF) $(22,23)$ measures in children nine of the 15 adult facets of EI, and has been shown to display acceptable levels of internal consistency in two separate samples and also displayed temporal stability $(a=0.79)$ similar to that found in adult samples. It has a self-rating version suitable for use in children as young as eight years old and other rating (in this case the mother) version which was suitable for the current sample.

\section{Procedure}

The mother-child pairs $(n=52)$ who participated in the first study had already consented to be recontacted for future studies. Permission was obtained from the participants' consultant obstetrician to recontact these 52 mothers by letter inviting them to take part in the follow-up study. Included in the letter were a participant information sheet which participants were asked to read, and a stamped addressed envelope providing participants an opportunity to decline participation in the study. Of those contacted, 39 responded positively and agreed to participate in the study. Due to lack of funding at this stage, we were unable to follow-up the full sample.

\section{Ethical considerations}

Ethical approval was granted in full from the Office of Research Ethics Committees in Northern Ireland (ORECNI) (reference number 05/Q2008/21) on 25th August 2012, Approval from the Northern Health and Social Care Trust was received on 28 December 2012. A substantial amendment to the study was approved by ORECNI on 6th July 2016 (Reference 12/ NI/0077).

\section{RESULTS}

The folate status of the experimental $(n=22)$ and control groups ( $\mathrm{n}=17$ ) was measured at 14 weeks and 36 weeks of gestation and again at birth. To ensure randomisation had been successful, these measurements were compared using nonparametric Mann-Whitney $U$-tests. Table 1 shows no significant difference between the experimental and control

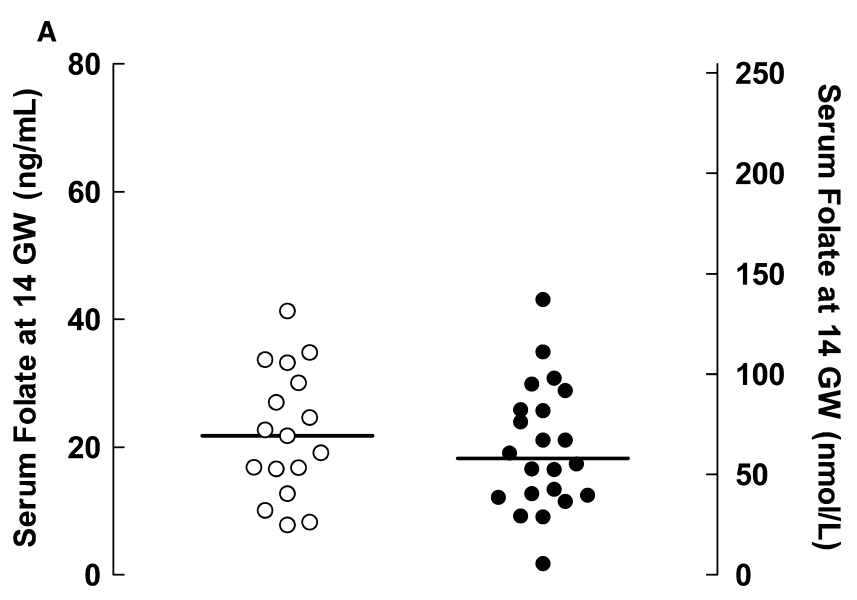

\section{B}

Placebo

FA

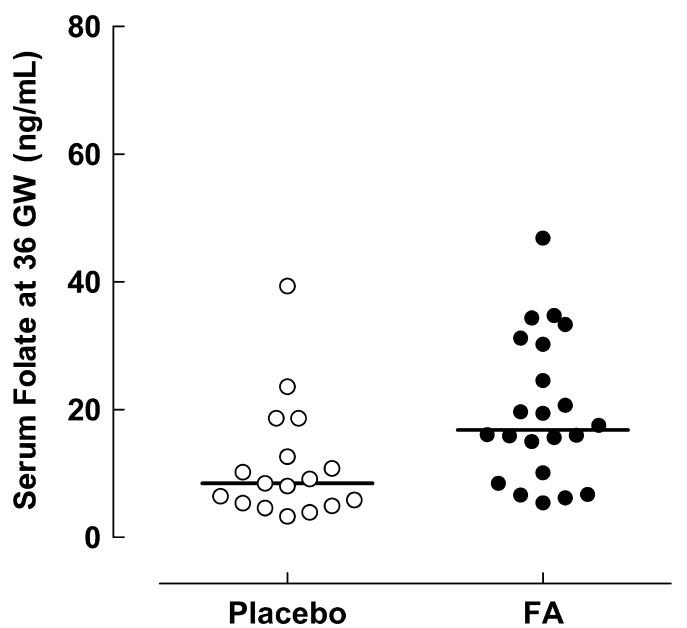

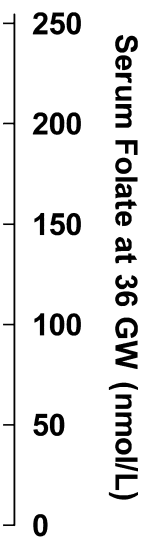

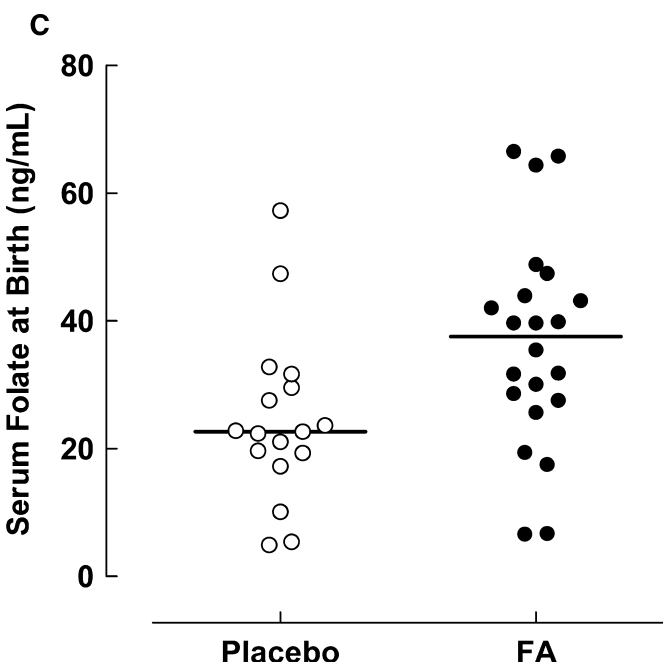

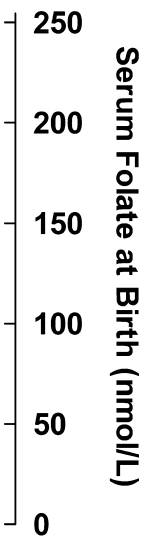

Figure 2 Mother's Serum Folate levels for experimental and placebo groups at 14 and $36 \mathrm{GW}$ and at birth.

group at the 14th gestational week $(\mathrm{GW})$, but there is a significant difference between the groups at the 36th GW and at birth as expected. These are illustrated in scatter dot diagrams in Figure 2A-C. 
To further test the quality of the RCT and ensure, there was no significant difference between the experimental and control group participants Mann-Whitney $U$-tests were conducted comparing the groups on a range of characteristics. Table 2 shows the range of characteristics compared between the groups.

The experimental $(n=22)$ and control groups $(n=17)$ were compared using Mann-Whitney $U$-tests and the main effects are summarised in Table 3.

Total scores for both EI and Resilience indicate a significant difference between experimental and control groups. SDQ scores highlighted a slight difference between the groups with the experimental group reporting less difficulties; however, this was not significant. These are illustrated in scatter dot diagrams in Figure 3.

\section{Emotional intelligence (TEIQue-CSF)}

Children assigned to the experimental group scored significantly higher on Total EI (Median $=64.50$, Interquartile range $=8.50$ ) compared to children in the control group (Median $=57.00$, Interquartile range $=7.00$, $\mathrm{p}=0.001)$. These results suggest that folic acid supplementation throughout pregnancy may have a positive effect on the children's EI at this age. There were 15 individual factors of EI measured using this scale (listed in Table 3) and 10 of these were nonsignificant. Significant values were as follows: Emotional Expressiveness $(p=0.006)$, Empathy $(p=0.026)$, Emotional Regulation
(Median $=\mathrm{p}=0.038)$, Adaptable $(\mathrm{p}=0.026)$ and Stress Management $(\mathrm{p}=0.03)$.

\section{Strengths and difficulties (SDQ)}

The total difficulties measured using the SDQ suggested a slight difference between the experimental group $($ Median $=6.00$, Interquartile range $=4.25)$ and control group $($ Median $=11.00$, Interquartile range $=12.50)$; however, this was a nonsignificant difference. The only individual facet of the scale to produce significant scores was conduct problems with the control group exhibited higher scores than the experimental group $(\mathrm{p}=0.038)$ (listed in Table 3).

\section{Resilience (RASP)}

Experimental group members scored significantly higher on total resilience (Median $=4.18$, Interquartile range $=0.31, \mathrm{p}=0.001)$ in comparison with members of the control group (Median $=3.75$, Interquartile range $=0.36, p=0.001)$. Findings suggest that children belonging to the experimental group are more resilient in comparison with their peers in the control group. The RASP measured seven separate facets of Resilience (listed in Table 3) all of which were significant values, these were as follows: Creativity $(p=0.008)$, Humour $(p=0.003)$, Independence $(p=0.001)$, Initiative $(p=0.017)$, Insight $(p=0.006)$, Relationships $(p=0.003)$ and Values Orientation $(\mathrm{p}=0.007)$.

Table 2 General characteristics of FASSTT mothers and children Trial participants

Maternal characteristics

\begin{tabular}{|c|c|c|c|c|c|c|}
\hline \multirow[b]{2}{*}{ Characteristics } & \multicolumn{2}{|c|}{ Treatment $(\mathrm{N}=22)$} & \multicolumn{2}{|c|}{ Control $(\mathrm{N}=17)$} & \multirow[b]{2}{*}{ Mann-Whitney $U$-value } & \multirow[b]{2}{*}{$\mathrm{p}$} \\
\hline & Median & Interquartile range & Median & Interquartile range & & \\
\hline Age (year) & 29.40 & 4.09 & 27.85 & 4.63 & 0.124 & -1.97 \\
\hline $\mathrm{BMI}\left(\mathrm{kg} / \mathrm{m}^{2}\right)$ & 25.53 & 5.28 & 24.55 & 3.67 & 0.517 & 0.984 \\
\hline \multirow[t]{2}{*}{ Education (years) } & 17.23 & 7.63 & 15.24 & 7.50 & 0.420 & 0.693 \\
\hline & \multicolumn{2}{|l|}{ Frequency } & \multicolumn{2}{|l|}{ Frequency } & $\chi^{2}$ & $\mathrm{P}$ \\
\hline Smokers & \multicolumn{2}{|l|}{$3 / 22$} & \multicolumn{2}{|l|}{$2 / 17$} & 0.030 & 0.625 \\
\hline Alcohol users & \multicolumn{2}{|l|}{$1 / 22$} & \multicolumn{2}{|l|}{$1 / 17$} & 0.035 & 0.688 \\
\hline Married & \multicolumn{2}{|l|}{$21 / 22$} & \multicolumn{2}{|l|}{$15 / 17$} & 1.382 & 0.417 \\
\hline Homeowner & \multicolumn{2}{|l|}{$17 / 22$} & \multicolumn{2}{|l|}{$13 / 17$} & 2.174 & 0.305 \\
\hline
\end{tabular}

\begin{tabular}{|c|c|c|c|c|c|c|}
\hline \multirow[b]{2}{*}{ Characteristics } & \multicolumn{2}{|c|}{ Treatment $(\mathrm{N}=22)$} & \multicolumn{2}{|c|}{ Control $(\mathrm{N}=17)$} & \multirow[b]{2}{*}{ Mann-Whitney U-value } & \multirow[b]{2}{*}{$\mathrm{p}$} \\
\hline & Median & Interquartile range & Median & Interquartile range & & \\
\hline Age at assessment (year) & 6.75 & 0.23 & 6.74 & 0.12 & 180.00 & 0.839 \\
\hline Birth weight (g) & 3394.06 & 612.97 & 3347.50 & 387.700 & 182.00 & 0.887 \\
\hline Length $(\mathrm{cm})$ & 51.44 & 2.28 & 50.77 & 1.6015 & 147.00 & 0.382 \\
\hline \multirow[t]{2}{*}{ Head size $(\mathrm{cm})$} & 33.93 & 1.53 & 34.68 & 1.60 & 147.00 & 0.375 \\
\hline & \multicolumn{2}{|l|}{ Frequency } & \multicolumn{2}{|l|}{ Frequency } & $\chi^{2}$ & p \\
\hline Breastfed from birth & \multicolumn{2}{|l|}{$9 / 22$} & \multicolumn{2}{|l|}{$9 / 17$} & 1.029 & 0.250 \\
\hline Gender, female & \multicolumn{2}{|l|}{$15 / 22$} & \multicolumn{2}{|l|}{$10 / 17$} & 0.365 & 0.393 \\
\hline
\end{tabular}


Table 3 Experimental versus control group descriptive statistics and main effects

\begin{tabular}{|c|c|c|c|c|c|c|}
\hline Variable & \multicolumn{2}{|c|}{ Experimental $(\mathrm{N}=22)$} & \multicolumn{2}{|c|}{ Control $(\mathrm{N}=17)$} & Mann-Whitney $U$-value & $\mathrm{p}$ \\
\hline \multicolumn{7}{|c|}{ Emotional intelligence scores (TEIQue-CSF) } \\
\hline Emotional expressive & 4.50 & 1.00 & 4.00 & 0.50 & 99.50 & 0.006 \\
\hline Empathy & 4.00 & 1.25 & 3.00 & 1.00 & 114.00 & 0.026 \\
\hline Self-motivation & 4.00 & 1.00 & 4.00 & 2.00 & 139.00 & 0.154 \\
\hline Social awareness & 5.00 & 1.00 & 4.00 & 1.00 & 131.00 & 0.076 \\
\hline Low impulsivity & 4.00 & 3.00 & 4.00 & 1.00 & 135.50 & 0.098 \\
\hline Emotional perceptive & 4.00 & 0.25 & 4.00 & 2.00 & 164.00 & 0.467 \\
\hline Self esteem & 4.50 & 1.00 & 4.00 & 1.00 & 132.50 & 0.082 \\
\hline Assertiveness & 4.00 & 0.25 & 4.00 & 1.00 & 137.50 & 0.123 \\
\hline Stress management & 4.00 & 0.50 & 3.00 & 1.00 & 115.50 & 0.030 \\
\hline \multicolumn{7}{|l|}{ SDQ scores } \\
\hline Difficulties total & 6.00 & 4.25 & 11.00 & 12.50 & 143.50 & 0.217 \\
\hline Emotional difficulties & 2.50 & 4.25 & 3.00 & 7.00 & 181.00 & 0.863 \\
\hline Conduct problems & 0.50 & 7.00 & 3.00 & 3.50 & 115.50 & 0.038 \\
\hline Hyperactivity & 3.00 & 4.50 & 4.00 & 7.00 & 161.00 & 0.455 \\
\hline Peer problems & 1.00 & 2.00 & 1.00 & 5.00 & 182.00 & 0.884 \\
\hline Prosocial behaviour & 10.00 & 1.00 & 9.00 & 4.00 & 160.00 & 0.426 \\
\hline \multicolumn{7}{|l|}{ RASP scores } \\
\hline Resilience total & 4.18 & 0.31 & 3.75 & 0.36 & 38.50 & 0.001 \\
\hline Creativity & 4.25 & 0.56 & 3.75 & 0.63 & 94.00 & 0.008 \\
\hline Humour & 3.88 & 1.00 & 3.25 & 1.13 & 83.00 & 0.003 \\
\hline
\end{tabular}

\section{Hierarchical multiple regression analysis (HMRA)}

The next stage in analysis was to test the proposed relationships using four separate HMRA as shown in Table 4. Firstly, EI was entered as the dependent variable with characteristics of the child including gender, weight, height and waist and head circumference entered as predictor variables in step 1 which accounted for a small amount of variance $(8 \%)\left(F_{5,32}=0.58 ; \mathrm{p}>0.05, \mathrm{R}^{2}=0.08\right.$, $\mathrm{R}^{2}$ Adjusted $\left.=-0.06\right)$. Maternal characteristics including BMI and age were added for step 2 which accounted for a further $17 \%$ of the variance $\left(F_{7,30}=0.87 ; \mathrm{p}>0.05, \mathrm{R}^{2}=0.17\right.$, $\mathrm{R}^{2}$ Adjusted $\left.=-0.025\right)$. The mother's level of folate measured at the 36th GW was added to the model on step 3 and accounted for a significant amount of the variance (42\%) $\left(F_{8,29}=0.2 .6 ; \mathrm{p}<0.05, \mathrm{R}^{2}=0.42, \mathrm{R}^{2}\right.$ Adjusted $\left.=0.26\right)$. The level of folate measured at 36th GW and the child's height had a significant partial correlation with EI.

A second HMRA was conducted with resilience as the dependent variable as shown also in Table 4. Again, this was a three-step HMRA with the child's characteristics (gender, weight, height and waist and head circumference) entered on step 1 and accounting for $11 \%$ of the variance $\left(F_{5,32}=0.78 ; \mathrm{p}>0.05, \mathrm{R}^{2}=0.11, \mathrm{R}^{2}\right.$ Adjusted $\left.=-0.03\right)$. The mother's BMI and age were added to the model on step 2 and accounted for $17 \%$ of the variance $\left(F_{7,30}=0.85\right.$; $\left.\mathrm{p}>0.05, \mathrm{R}^{2}=0.17, \mathrm{R}_{\text {Adjusted }}=-0.03\right)$. The folate level at 36th GW was added on step 3 explaining a total of 36\% of the variance $\left(F_{8,29}=2.0 ; \mathrm{p}>0.05, \mathrm{R}^{2}=0.36, \mathrm{R}^{2}\right.$ Adjusted $=$ 0.18 ). This predictor variable also produced a significant partial correlation.

The third HMRA was carried out with total difficulties as the dependent variable (Table 4). Similarly to the other regression analyses, this was a three-step HMRA with step 1 of the model (child characteristics) accounting for 4\% of the variance $\left(F_{5,32}=0.26 ; \mathrm{p}>0.05, \quad \mathrm{R}^{2}=0.04, \quad \mathrm{R}^{2}\right.$ Adjusted $=$ -0.11 ). Step 2 (Mothers BMI and age) accounting for $25 \%$ of the variance $\left(F_{7,30}=1.4 ; \mathrm{p}>0.05, \mathrm{R}^{2}=0.25\right.$, $\mathrm{R}^{2}$ Adjusted $=0.07$ ) and step 3 (folate level at $36^{\text {th }} \mathrm{GW}$ ) explaining a total of $28 \%$ of the variance $\left(F_{8,29}=1.4\right.$; $\mathrm{p}>0.05, \quad \mathrm{R}^{2}=0.28, \quad \mathrm{R}^{2}$ Adjusted $\left.=0.09\right)$. None of the 

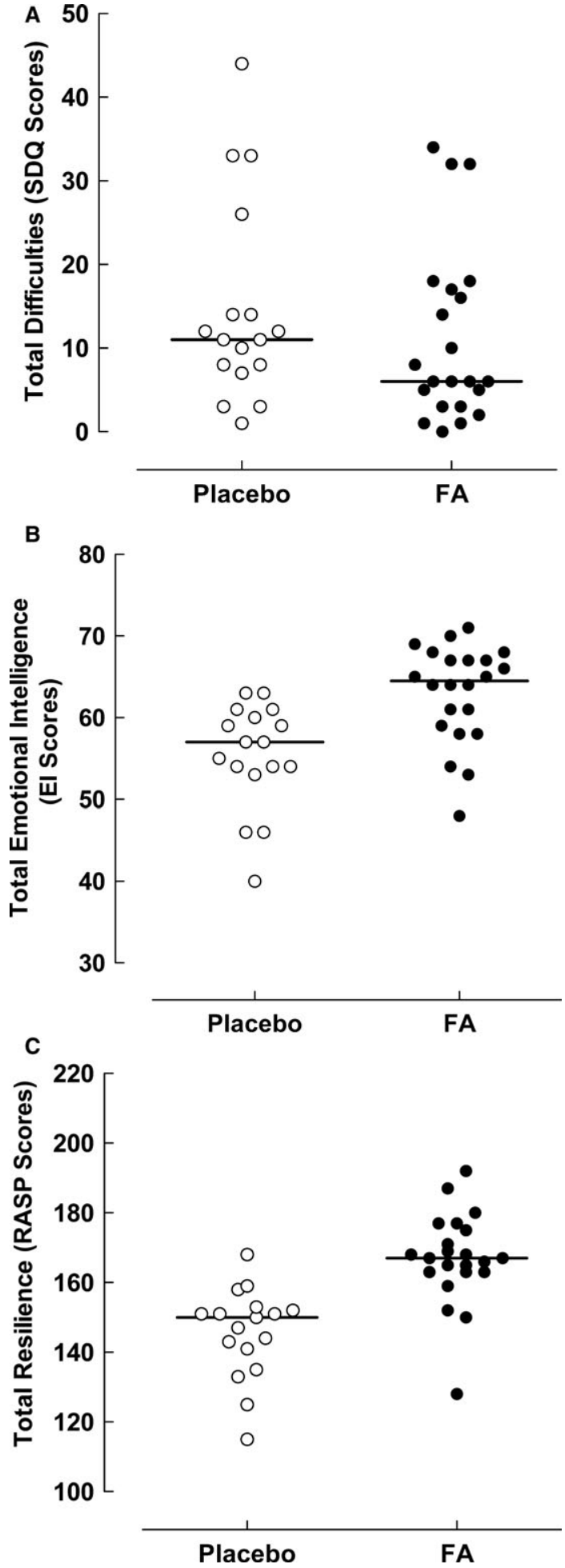

Figure 3 Total scores on SDQ, El and RASP for experimental and placebo groups.

individual variables produced significant partial correlations in this model.

The final HMRA used prosocial behaviour as the dependent variable. The first step of the model accounted for $17 \%$ of the variance $\left(F_{5,32}=1.3 ; \mathrm{p}>0.05, \mathrm{R}^{2}=0.17\right.$, $\mathrm{R}^{2}$ Adjusted $\left.=0.04\right)$ with the child's gender producing a significant partial correlation. After adding the mothers BMI and age to the model in step 2,23\% of the variance was accounted for $\left(F_{7,30}=1.25 ; \mathrm{p}>0.05, \quad \mathrm{R}^{2}=0.23\right.$, $\mathrm{R}^{2}$ Adjusted $\left.=0.05\right)$. The child's gender remained a significant partial correlation. Step 3 increased the total variance explained to $24 \%$ in total $\left(F_{8,29}=1.16 ; \mathrm{p}>0.05\right.$, $\mathrm{R}^{2}=0.24, \mathrm{R}^{2}$ Adjusted $=0.03$ ); however, no significant partial correlations were present in the final step of the model.

\section{DISCUSSION}

The aim of the present study was to test a subsample of participants from the original FASSTT study conducted in 2006 to assess strengths and difficulties, emotional intelligence and resilience in the children now in their seventh year of age. It was suggested that children of mothers who continued to take folic acid throughout pregnancy might have better psychosocial performance (exhibiting differences in strengths and difficulties, EI and resilience) compared to those whose mothers received placebo during the second and third trimester. Results demonstrated that children whose mothers were in the experimental group rated higher overall on EI and resilience as well as rating lower on the conduct problems dimension of the SDQ. To date, the literature has detailed the physical, cognitive and neurological benefits of folic acid supplementation with reasonable consistency $(4,6)$. However, no research exists on the effect of folic acid on positive psychological factors such as emotional intelligence and resilience. The present study provides some tentative evidence to suggest that a link may exist between the beneficial effect of folic acid on brain development and subsequent psychological factors in child development.

It was unlikely that folic acid supplementation directly affected the psychological attributes of the children. However, it is typical for children's physical, cognitive and psychological development to occur in synchrony and the more physically healthy the child, the more likely appropriate cognitive and psychological and emotional development would occur.

Previous research has linked folic acid supplementation with a number of positive effects. Children of mothers who had retrospectively reported taking the supplement showed increased general cognitive performance at ages three to four years (24). Language delay in children has been associated with lower levels of folate in foetal blood (25). In another study, folate supplementation was associated with improved language and motor development in children (26). Lower folate levels have also been associated with emotional and behavioural problems in children (27). The above research has looked at folate supplementation in the first trimester of pregnancy, yet the period 24-42 weeks is crucial for brain growth (28) but there is no evidence on the impact of folate during this period on cognitive and psychological development. 
Table 4 Hierarchical multiple regression with emotional intelligence, resilience, total difficulties and prosocial behaviour as separate dependent variables

\begin{tabular}{|c|c|c|c|c|c|c|c|c|c|}
\hline \multirow[b]{2}{*}{ Emotional Intelligence } & \multicolumn{3}{|c|}{ Model $1\left(r^{2}=0.08\right)$} & \multicolumn{3}{|c|}{ Model $2\left(r^{2}=0.17\right)$} & \multicolumn{3}{|c|}{ Model $3\left(r^{2}=0.42 *\right)$} \\
\hline & B & SE & $\beta$ & B & SE & $\beta$ & B & SE & $\beta$ \\
\hline Child's gender & -0.221 & 0.272 & -0.149 & -0.325 & 0.282 & -0.219 & -0.090 & 0.249 & -0.060 \\
\hline Weight (kg) & -0.083 & 0.100 & -0.384 & -0.080 & 0.099 & -0.368 & -0.152 & 0.087 & -0.702 \\
\hline Height (m) & 0.054 & 0.043 & 0.422 & 0.041 & 0.044 & 0.325 & 0.081 & 0.039 & $0.636 *$ \\
\hline Waist circumference $(\mathrm{cm})$ & -0.004 & 0.050 & -0.025 & 0.012 & 0.051 & 0.063 & 0.034 & 0.044 & 0.188 \\
\hline Head circumference (cm) & 0.001 & 0.055 & 0.002 & -0.004 & 0.054 & -0.013 & 0.033 & 0.047 & 0.122 \\
\hline Maternal BMI & & & & 0.018 & 0.029 & 0.114 & 0.008 & 0.025 & 0.048 \\
\hline Maternal age & & & & 0.044 & 0.032 & 0.278 & 0.015 & 0.028 & 0.095 \\
\hline \multirow[t]{2}{*}{ Folate level 36th GW } & & & & & & & 0.017 & 0.005 & $0.584 * *$ \\
\hline & \multicolumn{3}{|c|}{ Model $1\left(r^{2}=0.11\right)$} & \multicolumn{3}{|c|}{ Model $2\left(r^{2}=0.17\right)$} & \multicolumn{3}{|c|}{ Model $3\left(r^{2}=0.36\right)$} \\
\hline Resilience & B & SE & $\beta$ & B & SE & $\beta$ & B & SE & $\beta$ \\
\hline Child's gender & -0.061 & 0.156 & -0.070 & -0.057 & 0.165 & -0.066 & 0.063 & 0.153 & 0.072 \\
\hline Weight (kg) & 0.002 & 0.057 & 0.017 & -0.004 & 0.058 & -0.029 & -0.040 & 0.053 & -0.320 \\
\hline Height (m) & 0.019 & 0.025 & 0.261 & 0.020 & 0.026 & 0.275 & 0.040 & 0.024 & 0.547 \\
\hline Waist circumference $(\mathrm{cm})$ & -0.037 & 0.029 & -0.351 & -0.038 & 0.030 & -0.355 & -0.026 & 0.027 & -0.246 \\
\hline Head circumference $(\mathrm{cm})$ & 0.007 & 0.031 & 0.044 & 0.006 & 0.031 & 0.036 & 0.024 & 0.029 & 0.154 \\
\hline Maternal BMI & & & & 0.021 & 0.017 & 0.229 & 0.016 & 0.015 & 0.171 \\
\hline Maternal age & & & & 0.004 & 0.018 & 0.039 & -0.011 & 0.017 & -0.120 \\
\hline \multirow[t]{2}{*}{ Folate level 36th GW } & & & & & & & 0.008 & 0.003 & $0.510 *$ \\
\hline & \multicolumn{3}{|c|}{ Model $1\left(r^{2}=0.04\right)$} & \multicolumn{3}{|c|}{ Model $2\left(r^{2}=0.25\right)$} & \multicolumn{3}{|c|}{ Model $3\left(r^{2}=0.28\right)$} \\
\hline Total difficulties & B & SE & $\beta$ & B & SE & $\beta$ & B & SE & $\beta$ \\
\hline Child's gender & -2.299 & 4.343 & -0.099 & -0.900 & 4.187 & -0.039 & -2.334 & 4.307 & -0.101 \\
\hline Weight (kg) & -0.026 & 1.595 & -0.008 & 0.068 & 1.470 & 0.020 & 0.509 & 1.500 & 0.151 \\
\hline Height (m) & -0.312 & 0.691 & -0.158 & -0.163 & 0.654 & -0.082 & -0.403 & 0.676 & -0.204 \\
\hline Waist circumference $(\mathrm{cm})$ & 0.436 & 0.804 & 0.153 & 0.216 & 0.763 & 0.076 & 0.077 & 0.765 & 0.027 \\
\hline Head circumference $(\mathrm{cm})$ & 0.023 & 0.874 & 0.005 & 0.115 & 0.800 & 0.027 & -0.109 & 0.814 & -0.026 \\
\hline Maternal BMI & & & & -0.798 & 0.425 & -0.320 & -0.734 & 0.424 & -0.294 \\
\hline Maternal age & & & & -0.720 & 0.468 & -0.292 & -0.544 & 0.485 & -0.221 \\
\hline \multirow[t]{2}{*}{ Folate level 36th GW } & & & & & & & -0.101 & 0.081 & -0.228 \\
\hline & \multicolumn{3}{|c|}{ Model $1\left(r^{2}=0.17\right)$} & \multicolumn{3}{|c|}{ Model $2\left(r^{2}=0.23\right)$} & \multicolumn{3}{|c|}{ Model $3\left(r^{2}=0.24\right)$} \\
\hline Prosocial behaviour & B & SE & $\beta$ & B & SE & $\beta$ & B & SE & $\beta$ \\
\hline Child's gender & -2.518 & 1.060 & $-0.414^{*}$ & -2.469 & 1.114 & $-0.406^{*}$ & -2.220 & 1.163 & -0.365 \\
\hline Weight (kg) & 0.009 & 0.389 & 0.010 & 0.041 & 0.391 & 0.046 & -0.036 & 0.405 & -0.040 \\
\hline Height (m) & 0.018 & 0.168 & 0.034 & 0.020 & 0.174 & 0.038 & 0.062 & 0.183 & 0.119 \\
\hline Waist circumference $(\mathrm{cm})$ & 0.059 & 0.196 & 0.079 & 0.051 & 0.203 & 0.068 & 0.075 & 0.206 & 0.100 \\
\hline Head circumference $(\mathrm{cm})$ & 0.080 & 0.213 & 0.072 & 0.090 & 0.213 & 0.081 & 0.129 & 0.220 & 0.117 \\
\hline Maternal BMI & & & & -0.140 & 0.113 & -0.214 & -0.151 & 0.115 & -0.231 \\
\hline Maternal age & & & & -0.051 & 0.124 & -0.079 & -0.082 & 0.131 & -0.127 \\
\hline Folate level 36th GW & & & & & & & 0.018 & 0.022 & 0.151 \\
\hline
\end{tabular}

$* p<0.05 . * p<0.01$.

Given the above evidence, it could be speculated that the physical health benefits from supplementation could promote healthy psychological and emotional development with a range of mediating factors such as attachment style and parenting style (29). Although speculative, the underlying mechanism through which this effect may be transmitted is language and communication. Early language development is associated with earlier socio-emotional development. The dimensions of EI on which the children scored significantly higher were emotional expressiveness, empathy, emotional regulation, adaptability and stress management (30). In terms of resilience, these children scored significantly higher on dimensions of creativity, humour, independence, initiative, insight, relationships and values orientation. These are all areas one might expect to be enhanced from advanced language skills and cognitive development in general.

Research on folic supplementation has focused on the prevention of negative effects (5) and has not ventured into the potential for added benefits. This provides an interesting 
field for future research. These findings were encouraging, reinforcing the need for further research assessing the children themselves.

While the sample in this study was small, it was based on a randomised control trial thereby giving some credence to the findings. Although conclusions must be drawn with caution, this research presents a number of potential implications, the main one being a proposed policy recommendation for women to take folic acid for the duration of pregnancy rather than stopping at the end of the first trimester. The second is the potential for future research to explore the possible psychological and social development benefits and in line with this to try and identify the explanatory mechanism involved.

\section{CONFLICT OF INTEREST}

Nothing to declare.

\section{FUNDING}

This work was supported by the Health and Social Care Research \& Development Division of the Public Health Agency, Northern Ireland.

\section{References}

1. King JC. Physiology of pregnancy and nutrient metabolism. Am J Clin Nutr 2000; 71(Suppl.): 1218-25.

2. Lassi ZS, Salam RA, Haider BA, Bhutta ZA. Folic acid supplementation during pregnancy for maternal health and pregnancy outcomes. Cochrane Database Syst Rev 2013; 3.

3. Tamura T, Goldenburg R, Chapman V, Johnston K, Ramey S, Nelson K. Folate status of mothers during pregnancy and mental and psychomotor development of their children at five years of age. Paediatrics 2005; 116: 703-8.

4. Department of Health. Folic acid and the prevention of neural tube defects. Report form an expert advisory group. Heywood, UK: DOH Health Publication Unit, 1992.

5. Vollset SE, Refsum H, Irgens LM, Emblem BM, Tverdal A, Gjessing HK, et al. Plasma total homocysteine, pregnancy complications, and adverse pregnancy outcomes: the Hordaland Homocysteine study. Am J Clin Nutr 2000; 71: 962-8.

6. Department of Health. Folic acid and the prevention of disease. Report on Health and Social Subjects. Heywood: DOH Health Publication Unit, 2002.

7. Honein MA, Paulozzi LJ, Mathews TJ, Erickson JD, Wong LY. Impact of folic acid fortification of the US food supply on the occurrence of neural tube defects. JAMA 2001; 285: 2981-6.

8. Gross RL, Newberne PM, Reid JVO. Adverse effects on infant development associated with maternal folic acid deficiency. Nutr Rep Int 1974; 10: 241-8.

9. National Scientific Council on the Developing Child. Children's emotional development is built into the architecture of their brains: Working paper No. 2. 2004. Available at: http:// www.developingchild.net.

10. Durlak JA, Weissberg RP, Dymnicki AB, Taylor RD, Schellinger KB. The impact of enhancing students' social and emotional learning: a meta-analysis of school-based universal interventions. Child Dev 2011; 82: 405-32.

11. Greenberg M. Promoting Resilience in Children and Youth: preventive interventions and their interface with neuroscience. Ann N Y Acad Sci 1094; 2006: 139-50.
12. Mayer JD, Roberts RD, Barsade SG. Human abilities: emotional intelligence. Annu Rev Psychol 2008; 59: 507-36.

13. Masten A. Ordinary magic: resilience processes in development. Am Psychol 2001; 56: 227-38.

14. Erikson I, Cater A, Andershed A-K, Andershed H. What protects youths from externalising and internalising problems? A critical review of research findings and implications for practice. Aust J Guid Counsell 2011; 21: 113-25.

15. World Health Organization (WHO) \& UNICEF. Global strategy for infant and young child feeding. Geneva, Switzerland: World Health Organization, 2003.

16. Butler AS, Behrman RE, editors. Preterm birth: causes, consequences, and prevention. Washington (DC): National Academies Press, 2007.

17. Klein VC, Rocha LC, Martinez FE, Putnam SP, Linhares MBM. Temperament and behaviour problems in toddlers born preterm and very low birth weight. Span J Psychol 2013; 16: 18.

18. Wang S, Ge X, Zhu B, Xuan Y, Huang K, Rutayisire E, et al. Maternal continuing folic acid supplementation after the first trimester of pregnancy increased the risk of large-forgestational-age birth: a population-based birth cohort study. Nutrients 2016; 8: 493.

19. McNulty B, McNulty H, Marshall B, Ward M, Molloy AM, Scott JM, et al. Impact of continuing folic acid after the first trimester of pregnancy: findings of a randomized trial of Folic Acid Supplementation in the Second and Third Trimesters. Am J Clin Nutr 2013; 98: 92-8.

20. Wagnild GM. The Resilience Scale user's guide: for the US English version of the resilience scale and the 14 item resilience scale. Worden, Mont: The Resilience Centre, 2009.

21. Goodman R. The strengths and difficulties questionnaire: a research note. J Child Psychol Psychiatry 1997; 38: 581-6.

22. Mavroveli S, Petrides KV, Shove C, Whitehead A. Validation of the construct of trait emotional intelligence in children. Eur Child Adolesc Psychiatry 2008; 17: 516-26.

23. Petrides KV. Technical manual for the Trait Emotional Intelligence Questionnaires (TEIQue), 1st ed., 4th printing. London: London Psychometric Laboratory, 2009.

24. Villamor E, Rifas-Shiman SL, Gillman MW, Oken E. Maternal intake of methyl-donor nutrients and child cognition at 3 years of age. Paediatr Perinat Epidemiol 2012; 26: 328-35.

25. Roth C, Magnus P, Schjølberg S, Stoltenberg C, Surén P, McKeague IW, et al. Folic acid supplements in pregnancy and severe language delay in children. JAMA 2011; 306: 1566-73.

26. Julvez J, Fortuny J, Mendez M, Torrent M, Ribas-Fitó N, Sunyer J. Maternal use of folic acid supplements during pregnancy and four-year-old neurodevelopment in a population-based birth cohort. Paediatr Perinat Epidemiol 2009; 23: 199-206.

27. Steenweg-de Graaff J, Roza SJ, Steegers EAP, Hofman A, Verhulst FC, Jaddoe VW, et al. Maternal folate status in early pregnancy and child emotional and behavioral problems: the Generation R Study. Am J Clin Nutr 2012; 95: 1413-21.

28. Thompson RA, Nelson CA. Developmental Science and the media. Early brain development. Am Psychol 2001; 56: 5-15.

29. Diamond A. Interrelated and interdependent. Dev Sci 2007; 1: 152-8.

30. Cohen NJ. The impact of language development on the psychosocial and emotional development of young children. In: Tremblay RE, Boivin M, Peters RDV, editors. Rvachew S, Topic ed. Encyclopedia on early childhood development [online]. Available at: http://www.child-encyclopedia.com/la nguage-development-and-literacy/according-experts/impact-la nguage-development-psychosocial-and. (accessed January 2010). Accessed February 1, 2018. 